\title{
Italian space scientists win round in funding
}

Munich. The Italian government last week came down on the side of space scientists in their battle to recover millions of dollars now going to commercial space projects.

Antonio Roberti, Italian research minister, has told the Italian Space Agency (ASI) that it must adhere to a law that requires the agency to spend 15 per cent of its budget on research. The president of ASI, Luciano Guerriero, has been deducting Italy's contribution to the European Space Agency (ESA) - of which only about one-seventh goes for research - and other costs before calculating the share that researchers are entitled to receive.

The problem, which has been building up since ASI was created in 1988, came to a head last year when the agency's science advisory committee blocked the agency from spending any of its 1991 budget in protest at ASI's policy. Its actions effectively paralysed many international research collaborations (see Nature 356, 647; 1992). Roberti also reprimanded Guerriero for funding some research projects without first consulting the advisory committee, a further contravention of the regulations.

The minister's intervention vindicates the committee's chairman, Remo Ruffini of the University of Rome. Ruffini had been criticized by scientists and by members of his own committee for exercising his right to refuse to approve any award in order to increase the amount of money going to research. Committee members now say that they are united behind Ruffini and have dropped their demand that he resign.

Roberti, in his directive to Guerriero, supported Ruffini's tactics. He said he was "very sensitive to the unhappiness of the scientific community" and he demanded that ASI resolve the issue immediately. Roberti also said that ASI's decision to fund some projects on its own was unconstitutional. The agency's support for SAX, an expensive X-ray astronomy telescope, despite the advisory committee's belief that the science is out of date, had contributed to the breakdown in relations between the two bodies.

Ruffini will now allow ASI to spend all of its available research money. That amount, some 46,000 million lira, falls well short of the 68,000 million lira that researchers had expected to receive in 1991 and the request for 74,000 million lira that the committee made last autumn in the midst of its battle with ASI.

But the dispute is far from over. Ruffini wants the government to restore all of the funds withheld by ASI from researchers through the years. Guerriero says that the question of retrospective funding is being reviewed.

Guerriero also denies that his interpretation of the law penalized scientists, and says that the difference, if it exists at all, is trivial. "International research programmes paid for from our ESA contribution will still have to be deducted from the 15 per cent", he says.

Ruffini, in turn, accuses Guerriero of taking a cavalier attitude towards govern- ment funds, and insists that the additional money due to science is substantial. "It will probably be around 40 billion lira", he says, an amount Guerriero disputes.

The debate over money obscures what some scientists believe is a more serious problem facing ASI - its system of awarding grants. Giovanni Bignami of the University of Cassino, whose work has been delayed because of the infighting, says that fundamental changes are needed. "Now that the ministry has take a firm stand on how much money [for research] should be given, it must also find a means to divide the money in a professional and mature way", he says.

Bignami would like to see ASI use the same type of independent peer-review panels that are common in other space agencies. At present, all work funded by ASI is selected by the advisory committee, which includes researchers in a variety of applied areas such as telecommunications and robotics. The more fundamental scientists feel that their views are being ignored, and they fear that those with commercial interests may be exerting too great an influence on the selection process.

Robertis said that the ministry will not consider ASI's provisional budget for 1992 - submitted last month, seven months late - until ASI has solved its research funding problems. He has given ASI two months to put its house in order. In the meantime, the committee is developing its recommendations on the assumption of a significant increase in its funding.

Alison Abbott

\section{Europe decides manned space costs too much for now}

Munich. Plans for Europe's manned space programme have been shelved, possibly forever, as the project becomes too costly for member states of the European Space Agency (ESA) to afford.

Jean-Marie Luton, director-general of ESA, announced last week that his agency will recommend a postponement until at least 2005 of plans for the space plane Hermes and the man-tended free flyer that is part of the space station Columbus. Instead, the technology developed so far will be displayed on an unmanned demonstrator to be launched in 1998 with the hope that it will attract investors from outside Europe. The missions were originally scheduled to be ready in 1998 .

In the meantime, the ESA will concentrate on its Earth observation projects, in particular those that monitor the environment. Those projects will benefit from the US $\$ 700$ million to be saved by postponing Hermes and the free flyer.

The recommendation is expected to be adopted by ESA delegates meeting later this month in Paris. It would then be officially approved at a ministerial meeting in November in Spain.

The announcement came as no surprise to the space research community. Rumours had been circulating for months that an independent European manned space programme was no longer feasible in the current economic and political environment. The cost of Hermes has risen by 40 per cent in five years, to a current estimate of US $\$ 7,500$ million.

Last November, ministers from ESA member countries voted to delay the Hermes and Columbus projects for one year to give them time to reconsider their rising costs and to search for new partners. That action followed a decision by the German government to reduce its funding in real terms.

The immediate problem arose after the German space agency, DARA, was told that its annual budget would be increased by no more than 2.5 per cent in the next few years, well below the 10 per cent rate that is needed to meet the country's commitment to European space programmes that Germany made in 1987. That left ESA with a shortfall of about US $\$ 650$ million, a gap that other member states were unwilling to fill.

But the president of DARA, Wolfgang Wild, says that economic considerations were not the only reason for delaying the projects. "The political changes in eastern Europe have opened up new possibilities for cooperation that we must investigate", he says.

ESA members have spent the past few months trying to forge links with other countries, specifically Russia. ESA hopes that tapping into Russia's expertise in manned and unmanned space exploration will lower the cost of its own programme.

"The man-tended free flyer is not so important now if Europe can have access to the Russian space station Mir", says Wild. Still, overtures to the newly formed Russian space agency have yet to produce any tangible results.

Alison Abbott 